\title{
Multivariate hierarchical model for physical inactivity among public school children
}

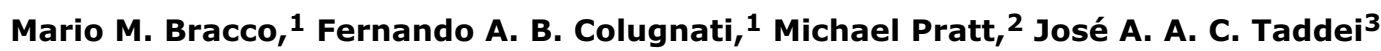

\begin{abstract}
Objective: To identify biological and sociodemographic factors associated with physical inactivity in public school children.

Methods: Parents of 2,519 children ( $49.3 \%$ of whom were girls), aged 7 to 10 years (mean $=7.6 \pm 0.9$ years), from eight public schools in São Paulo, Brazil, completed a self-administered questionnaire. We used multiple correspondence analysis to identify groups of responses related to levels of physical activity and inactivity and to obtain an optimal scale. The cluster analysis identified groups of active and inactive children. The analysis of the receiver operator characteristic (ROC) curve, for the study of diagnostic properties of a simplified scale for physical inactivity derived from the optimal scale, revealed that a cutoff point of 3 had the best sensitivity and specificity, being therefore used as the outcome variable in the regression model. A multivariate hierarchical model was built, including distal and proximal categorical variables, with a $\mathrm{p}<0.05$.

Results: Physical inactivity was positively associated with biological factors such as being overweight, being older than 7.5 years, being a female, and having a good appetite, and with socioeconomic factors such as having garbage collected less than twice a week and having mothers who work outside the home.

Conclusion: The results are consistent with published data about determinant factors of physical activity and inactivity among children, showing that questionnaires answered by parents and submitted to a sophisticated statistical analysis can be used in population-based studies involving children younger than 10 years old.
\end{abstract}

J Pediatr (Rio J). 2006;82(4):302-7: Physical activity, schools, questionnaires, children.

\section{Introduction}

Sedentary lifestyle among children constitutes a public health problem, due to its association with childhood obesity and with a worse health status in adulthood. 1-3 Even though physical activity has been widely investigated in late childhood and in adolescence, few studies have included children younger than 10 years old. ${ }^{4}$ The lack of

1. Doutor, Universidade Federal de São Paulo - Escola Paulista de Medicina (UNIFESP-EPM), São Paulo, SP, Brasil.

2. Director, WHO Collaborating Center for Physical Activity and Health Promotion, Research and Development Team Leader, Physical Activity and Health Branch, Division of Nutrition and Physical Activity, Centers for Disease Control and Prevention (CDC), Atlanta, GA, USA.

3. Professor livre-docente e chefe, Disciplina de Nutrologia, Departamento de Pediatria, UNIFESP-EPM, São Paulo, SP, Brasil.

Manuscript received Oct 19 2005, accepted for publication Mar 222006.

Suggested citation: Bracco MM, Colugnati FA, Pratt M, Taddei JA. Multivariate hierarchical model for physical inactivity among public school children. J Pediatr (Rio J). 2006;82:302-7. reliable measures, pointed out by children or by their parents, in addition to the lack of a validated method that can be used in large population-based studies, may prove a hindrance. ${ }^{5}$

Sallis et al. ${ }^{6}$ developed a non validated index to detect determinant factors of physical activity, which consists of an 11-item questionnaire to be answered by children or adolescents and by their parents, in a nationally representative sample of male and female students attending grades 4 th to 12 th in the United States. The authors took for granted that multiple items provide far better information than a single item. They concluded that the high internal consistency of the score added reliability to determinant factors identified by the study.

A multicenter study conducted in the United States revealed acceptable levels of correlation for reproducibility and low correlations for validity, with regard to the use of accelerometers, in the questionnaire used for the 
intervention. However, the authors underscored that questionnaires for data collection from young-age children should be improved in future studies. ${ }^{7}$

The identification of factors associated with physical activity in different life cycles is crucial for planning efficient and effective interventions. Sophisticated techniques have been developed for the identification and analysis of these factors, with the increasing use of ecological models for the promotion of physical activity which, in turn, generate highly complex data that are difficult to interpret. ${ }^{8}$ Particularly, hierarchical conceptual models have been used to elucidate several factors that determine specific health or behavioral conditions, as well as the interrelationships that could lead to an outcome. ${ }^{9}$ The Guide to Community and Preventive Services and the Centers for the Disease Control and Prevention's (CDC) Physical Activity Evaluation Handbook recommend that a logical framework should be a fundamental step in the design of community-based physical activity interventions, describing the intervention phases and the intended goals. 10,11

The aim of the present study is to identify factors associated with physical inactivity among public school children by building a hierarchical model based on information from a self-administered questionnaire answered by parents, and on a scale for the quantification of categorical variables and their interrelationships, as outcome variable in the regression model.

\section{Methods}

The study included male (50.7\%) and female $(49.3 \%)$ children aged 7 to 10 years ( $X=7.6 \pm 0.9$ years) enrolled in the 1 st and 2 nd grades of eight elementary public schools located in the neighborhood of Vila Mariana in São Paulo, Brazil. These children took part in a school-based intervention to reduce childhood obesity risk that focused on improving nutritional habits and PA levels (Risk Reduction of Illness and Death in Adulthood - The RRIDA Project). We developed a pre-tested, pre-coded structured parent self-report questionnaire in order to collect information about children's behaviors and habits as well as their practice of recreational physical activity and transportation to school. We sent out 2,800 questionnaires to the parents or surrogates of all students enrolled in the 1st and 2nd grades of eight schools. The questionnaires were returned, on average, 3 days afterwards, with the signed consent form, which allowed the participation of the children in the study. The response rate amounted to $89.9 \%$, totaling 2,519 questionnaires. The data were entered twice in the database in order to minimize possible typos.

A partnership for the development of the project was established with the State Department of Education and schools' administration for the Central and Southern
Regions of the city of São Paulo. The study was approved by the Research Ethics Committee of Universidade Federal de São Paulo (UNIFESP).

The field team consisted of nutritionists and physical education teachers, who were previously trained for data collection in order to standardize the procedures and provide more accurate and precise weight and height measurements. We used digital Filizola ${ }^{\circledR}$ scales (with capacity for $150 \mathrm{~kg}$ with a precision of $50 \mathrm{~g}$ ), for weight measurement in kilograms, and Seca $208^{\circledR}$ anthropometric tapes for height measurement in centimeters. The students wore shorts and T-shirts and were asked to stand barefoot in an upright position with their heels together, and with their shoulders and buttocks touching the wall. A handbook describing the project, enhancing planning, data collection, and analysis was developed by the research team and made available to the Department of education and schools' administration, principals and classroom teachers.

Children were categorized as overweight or non overweight. Overweight was defined as a weight-forheight two standard deviations (z scores) above the NCHS/WHO reference median. ${ }^{12}$ Age was measured in months, calculated by day of birth up to the day on which the data were collected. Birth weight was classified as either less than or greater than $3,500 \mathrm{~g}$.

Selected questions from the questionnaire related to children's leisure-time places, means of transportation to and from school, types of playing, perception of parents about the level of physical activity of their children compared to that of other children; sports practice outside of school; amount of sleep during the night and during the day; amount of TV viewing, and eating while watching TV, which indicated more or less active children's profiles, according to evidence-based factors for physical activity, as described in the literature ${ }^{13}$ (Table 1).

Socioeconomic status was estimated based on the answers to the questions about the frequency of weekly garbage collection, mother's employment status, and maternal level of education. In order to determine children's eating habits, we included questions about the age at which bottle-feeding was discontinued and about the child's current appetite (Table 2).

We applied multiple correspondence analysis, which identified different profiles of physical activity and inactivity, according to the answers of questions about children's habits, which have created a physical activity/inactivity construct. ${ }^{14}$ Out of these questions, we identified four variables that provided the highest discrimination coefficient in the construct. Cluster analysis, by the $K$-means algorithm, categorized the different clusters of activity/inactivity into active and inactive groups. We arbitrarily assigned value 1 to physical inactivity and 0 to physical activity in the questions regarding physical activity attributes. The sum of these values ( 0 to 4 ) originated a simplified physical 
Table 1 - Variables regarding children's habits (physical activity and daily habits)

\begin{tabular}{|c|c|c|}
\hline Variables & Indicates physical activity & Indicates physical inactivity \\
\hline $\begin{array}{l}\text { What does your child most like to do } \\
\text { in his or her leisure time? }\end{array}$ & $\begin{array}{l}\text { Playing soccer, riding a bike, } \\
\text { playing tag }\end{array}$ & $\begin{array}{l}\text { Watching TV, drawing, } \\
\text { playing with dolls }\end{array}$ \\
\hline $\begin{array}{l}\text { During the day and outside of school, } \\
\text { where does your child play most of the time? }\end{array}$ & $\begin{array}{l}\text { On the street, } \\
\text { in the backyard }\end{array}$ & $\begin{array}{l}\text { At home, } \\
\text { at a neighbor's house }\end{array}$ \\
\hline $\begin{array}{l}\text { How active is your child } \\
\text { compared to other children? }\end{array}$ & $\begin{array}{l}\text { More active, } \\
\text { just as active }\end{array}$ & $\begin{array}{l}\text { Less active, } \\
\text { do not know }\end{array}$ \\
\hline How many hours a day does your child watch TV? & Up to 4 hours & Over 4 hours \\
\hline Does your child usually eat meals while watching TV? & No & Yes \\
\hline Does your child practice any sport outside of school? & Yes & No \\
\hline How many hours does your child sleep every night? & From 7 to 10 hours & $\begin{array}{l}\text { Less than } 7 \text { hours, } \\
\text { more than } 10 \text { hours }\end{array}$ \\
\hline Does your child usually sleep during the day? & No & Yes \\
\hline If so, how many hours? & $<2$ & $>2$ \\
\hline
\end{tabular}

Table 2 - Socioeconomic and nutritional variables

\begin{tabular}{|c|c|c|}
\hline Variables & $\begin{array}{c}\text { Higher } \\
\text { socioeconomic status }\end{array}$ & $\begin{array}{c}\text { Lower } \\
\text { socioeconomic status }\end{array}$ \\
\hline \multicolumn{3}{|l|}{ Socioeconomic status } \\
\hline Garbage collection & $>$ twice a week & < twice a week \\
\hline Maternal level of education & $>4$ th grade & $<4$ th grade \\
\hline Mother working outside the home & No & Yes \\
\hline Variables & Best dietary habits & Worst dietary habits \\
\hline \multicolumn{3}{|l|}{ Dietary patterns } \\
\hline At what age was your child weaned from bottle-feeding? & $<2$ years & $>2$ years \\
\hline Children's appetite during meals & Very good; good; fair & Very poor and poor \\
\hline
\end{tabular}

inactivity scale. Later on, we performed a receiver operator characteristic (ROC) curve analysis, in order to assess the diagnostic properties of this five-point scale in relation to the optimal scale generated by multiple correspondence analysis. The cutoff point greater than or equal to 3 was the most appropriate for the detection of physical inactivity, being used as outcome variable in the logistic regression analysis.

The logistic regression model was adjusted in order to estimate the odds ratios for physical inactivity between the two groups, according to biological, socioeconomic, and eating variables. We used a hierarchical model and classified the explanatory variables as proximal and distal in the multivariate model. ${ }^{11}$ In the bivariate analysis, the variables with a $p$ value less than 0.2 were included in the multivariate analysis. In this model, we established a $p$ value less than 0.05 as statistically significant.

\section{Results}

All significant variables $(p<0.05)$ and the bottlefeeding weaning variable $(p<0.2)$ were selected for the hierarchical model. The biological and eating variables were defined as proximal determinants and the socioeconomic variables, as distal determinants. Overweight was positively associated with physical inactivity 
in $52 \%$ of subjects. Being a female and being older than 7.5 years was also positively associated with physical inactivity, and so was having a good appetite. There is a greater risk for physical inactivity among children who live in households where garbage is collected less than twice a week, and also among those whose mothers work outside the home. No association was found with birth weight, maternal level of education and late weaning from bottle-feeding (Tables 3 and 4 ).

\section{Discussion}

Hierarchical models include concepts about biological and social variables that describe hierarchical relationships between them and the outcome in a given health condition or behavior. ${ }^{9}$ In this study, the outcome variable included a simple scale of physical activity/ inactivity attributes associated with more or less active behaviors, thus providing higher statistical power to the multivariate hierarchical model.

In spite of the narrow age difference among the sampled children, there was a positive association between physical inactivity and chronological age. Girls were at a greater risk for physical inactivity, indicating that, even in younger children, age and gender can play an important role in the adoption of a sedentary lifestyle.
Trost et al. ${ }^{4}$ assessed a population-based sample of students attending grades 1st to 12 th in the United States by using accelerometers, and concluded that boys were consistently more active than girls in vigorous and moderate physical activities. Moreover, although elementary school students were significantly more active than middle and high school students, the largest differences were found in late elementary school grades, which indicates that the paucity of descriptive studies involving children younger than 9 years may not detect such findings in younger children, and therefore, it is necessary that further studies be carried out to assess the mediating factors related to the differences between age and gender using population-based samples.

The association between obesity and physical inactivity in childhood and adolescence has been widely described. 1,2 Bracco et al. ${ }^{3}$ found out that the amount of energy spent by overweight children aged 9 to 11 years in physical activities, measured by accelerometers, was twice as high as that of normal-weight children, observed in a crosssectional study conducted in the outskirts of São Paulo, Brazil. In this study, the positive association with overweight highlights the necessity to develop policies that can tackle this problem in the school environment.

Even though some studies have shown that exercise can be associated with an increase in energy intake as a

Table 3 - Biological (proximal) determinants of physical inactivity in children attending the 1st and 2nd grades at public schools of São Paulo

\begin{tabular}{|c|c|c|c|c|}
\hline Variables & $\begin{array}{c}\text { Crude odds ratio } \\
(95 \% \mathrm{CI})\end{array}$ & $\mathbf{p}$ & $\begin{array}{c}\text { Adjusted odds ratio } \\
(95 \% \mathrm{CI})\end{array}$ & $\mathbf{p}$ \\
\hline Overweight & $1.53(1.17-1.99)$ & 0.001 & $1.52(1.16-2.00)$ & 0.002 \\
\hline Female & $1.69(1.42-2.00)$ & 0.000 & $1.76(1.47-2.11)$ & 0.000 \\
\hline Age $>7.5$ years & $1.23(1.04-1.47)$ & 0.014 & $1.29(1.08-1.55)$ & 0.005 \\
\hline Good appetite & $2.09(1.41-3.09)$ & 0.000 & $1.94(1.29-2.91)$ & 0.001 \\
\hline Bottle-feeding $>2$ years & $1.13(0.94-1.36)$ & 0.182 & $1.13(0.93-1.37)$ & \\
\hline Birth weight $>3,500 \mathrm{~g}$ & $0.94(0.76-1.17)$ & 0.615 & & \\
\hline
\end{tabular}

$95 \% \mathrm{Cl}=95 \%$ confidence interval

Table 4 - Socioeconomic (distal) determinants of physical inactivity in children attending the 1st and 2nd grades at public schools of São Paulo

\begin{tabular}{|c|c|c|c|c|}
\hline Variables & $\begin{array}{c}\text { Crude odds ratio } \\
\qquad(95 \% \mathrm{CI})\end{array}$ & $\mathbf{p}$ & $\begin{array}{c}\text { Adjusted odds ratio } \\
(95 \% \mathrm{CI})\end{array}$ & $\mathbf{p}$ \\
\hline Mother's schooling $<4$ years & $0.96(0.80-1.14)$ & 0.664 & & \\
\hline Mother working outside the home & $1.62(1.31-1.99)$ & 0.000 & $1.60(1.28-1.99)$ & 0.000 \\
\hline Garbage collection < twice a week & $1.31(1.11-1.56)$ & 0.002 & $1.31(1.09-1.57)$ & 0.003 \\
\hline
\end{tabular}

$95 \% \mathrm{Cl}=95 \%$ confidence interval. 
way to compensate for energy expenditure, short-term experimental studies did not find an increase in appetite among adults after exercise. ${ }^{15}$ Moore et al. ${ }^{16}$ analyzed the relationship with appetite, represented by energy intake after high- and low-intensity exercises in girls aged 9 to 10 years and in sedentary controls. The authors did not find any evidence of compensation for energy expenditure through an increase in food intake. Ad libitum energy intake was similar under sedentary and exercise conditions. da Costa Ribeiro et al. ${ }^{17}$ observed that appetite at mealtime was positively associated with obesity in a case-control study carried out with a sample of participants of the RRIDA Project. In this model, appetite was positively associated with physical inactivity, indicating that it can be mediated by obesity, but that it can also have an independent role, determining physical inactivity. In the model, we also assessed whether changes in eating behavior could be associated with the outcome by using the age at which children were weaned from bottlefeeding as a variable. Although no association was found in the adjusted model, some studies have suggested that the late introduction of solid foods and early weaning may contribute to a less active pattern among infants, yielding discrepant and inconclusive results. 18,19

The social variables showed that low socioeconomic status is associated with physical inactivity, although the study population has a low socioeconomic status as a whole. However, level of education and the mother's employment status, as well as the frequency of garbage collection, may distinguish the children who live in more or less affordable families. da Costa Ribeiro et al. ${ }^{17}$ observed a strong positive association between maternal level of education and obesity in this population of students. Taddei et al. ${ }^{20}$ found the same association when analyzing data from the Brazilian National Survey on Health and Nutrition (Pesquisa Nacional em Saúde e Nutrição, PNSN) in children younger than 5 years from northeastern Brazil, but an inverse association in southeastern Brazil, and concluded that level of education may play an important role in the selection of healthy behaviors. Oschlaeger et al. ${ }^{21}$ found that adolescents, in southern Brazil, whose mothers had attended school for less than 4 years were twice as likely to lead a sedentary lifestyle as those whose mothers had attended school for 9 years or more. In our study, the behavior of this variable seems more closely related to that of underdeveloped Brazilian regions, where most mothers attended school for less than 8 years (data not shown).

There is a positive association between mother's employment status and physical inactivity in the adjusted model. There are some explanations to this finding. In São Paulo, $21.3 \%$ of women are household heads who live without a partner. ${ }^{22}$ Usually, children stay at home, with the older ones taking care of the younger ones. Thus, there are fewer opportunities for physical activity outside of school among these children. Mothers who need to work and leave their children home alone seem probably to be in more vulnerable social condition than the others who have the possibility to take care of their children. To our knowledge, there are no studies on this social issue related to children's health behavior, although some authors have described the coexistence of obesity and malnutrition among members of a same family, in industrialized and in developing countries, which could be a marker for the development of chronic diseases. ${ }^{23,24}$ Iyer \& Monteiro 25 found that children and adolescents younger than 20 years old belonging to vulnerable low-income populations of Rio de Janeiro are at greater risk of death when mothers are the household's head, compared to mothers who are living in the same region. The authors also observed a greater risk of death among children who live in slums. These urban clusters are characterized by the lack of social capital, and community services are scarce and insufficient. The frequency of garbage collection allowed classifying the study population into different socioeconomic levels based on the place of residence. There was a positive association between this variable and physical inactivity, which suggests that neighborhoods where community services are scarce can contribute towards a sedentary lifestyle among children. Unplanned urbanization of public spaces and the increasing crime rates in urban centers are a hindrance to the practice of physical activity among children, resulting in inactivity, due to the lack of leisure activities and of activities that involve low energy expenditure, especially in low-income communities. Recently, a cross-sectional study carried out in the United States, whose aim was to identify determinants of physical activity among children aged 9 to 13 years, revealed remarkable differences between different socioeconomic levels regarding the lack of infrastructure and of public safety. ${ }^{26}$ In São Paulo, the rate of violence in low-income communities is virtually sevenfold higher than in highincome neighborhoods, affecting especially young adults. 27

This study had some limitations, as described next. Its cross-sectional design does not allow making inferences about cause and effect between mediating factors associated with physical inactivity, even though some longitudinal studies have found some association between the determinants analyzed in the hierarchical model, such as overweight, age, and gender. ${ }^{2,28}$ In this study, the data analyses by individual characterization detected some differences in categorical variables and identified key determinants of physical inactivity. In addition to the limitations of questionnaires, which have been widely described for this age group, 4,29 the use of a nonvalidated questionnaire in this study prevents us from drawing solid conclusions about the level of physical activity among children; therefore, we can only suggest 
this behavior based upon the attributes of physical activity described in the questionnaire. On the other hand, our results are consistent with published data on determinants of physical activity and inactivity, making us infer that questionnaires answered by parents or surrogates, when submitted to sophisticated statistical analyses, can be a useful and feasible tool in population-based studies involving children younger than 10 years, who cannot answer the questionnaires on their own. The multiple correspondence analysis validated the physical inactivity attributes selected in the questionnaire for the construction of the optimal scale. The validation of these questions by means of direct monitoring tools or by the double labeled water method should be explored by future studies.

The hierarchical conceptual model for public school children shows that physical inactivity is consistently associated with being a female, being older than 7.5 years, being overweight, and having a good appetite. Physical inactivity is also associated with mothers who work outside the home and with a frequency of garbage collection less than twice a week. According to these findings, further studies are necessary for the validation, reproducibility and reliability of the questionnaires answered by parents or surrogates, so that they can be improved as tools. Moreover, a wider range of variables should be included in order to describe the behavior of physical activity among children in developing countries.

\section{Acknowledgements}

To Tom Schmid, David Brown, Candace Rutt and Janet Fulton, from the CDC's Physical Activity and Health Branch, Division of Nutrition and Physical Activity, for their invaluable comments and suggestions to improve this work.

Thanks to CAPES for the financial support granted to the first author as invited researcher at CDC.

\section{References}

1. Fonseca VM, Sichieri R, da Veiga GV. Fatores associados à obesidade em adolescentes. Rev Saude Publica. 1998;32:541-9.

2. Berkey $C S$, Rockett $H R$, Field $A E$, Gillman $M W$, Frazier $A L$, Camargo CA Jr., et al. Activity, dietary intake, and weight changes in a longitudinal study of preadolescent and adolescent boys and girls. Pediatrics. 2000;105:E56.

3. Bracco M, Ferreira M, Morcillo A, Colugnati F, Jenovesi J. Gasto energético em crianças de escolas públicas obesas e não obesas. Rev Bras Cienc Mov. 2002;10:29-35.

4. Trost SG, Pate RR, Sallis JF, Freedson PS, Taylor WC, Dowda M, et al. Age and gender differences in objectively measured physical activity in youth. Med Sci Sports Exerc. 2002;34:350-5.

5. Sallis JF, Saelens BE. Assessment of physical activity by selfreport: status, limitations, and future directions. Res Q Exerc Sport. 2000;71:S1-14.

6. Sallis JF, Prochaska JJ, Taylor WC, Hill JO, Geraci JC. Correlates of physical activity in a national sample of girls and boys in grades 4 through 12 . Health Psychol. 1999;18:410-5.
7. Treuth MS, Sherwood NE, Baranowski T, Butte NF, Jacobs DR, Jr., McClanahan B, et al. Physical activity self-report and accelerometry measures from the Girls health Enrichment Multisite Studies. Prev Med. 2004;38 Suppl:S43-9.

8. Duncan SC, Duncan TE, Strycker LA, Chaumeton NR. A multilevel approach to youth physical activity research. Exerc Sport Sci Rev. 2004;32:95-9.

9. Victora CG, Huttly SR, Fuchs SC, Olinto MT. The role of conceptual frameworks in epidemiological analysis: a hierarchical approach. Int J Epidemiol. 1997;26:224-7.

10. Centers for Disease Control and Prevention, US Department of Health and Human Services. Physical activity evaluation handbook. Atlanta: CDC; 2002.

11. Kahn EB, Ramsey LT, Brownson RC, Heath GW, Howze EH, Powell KE, et al. The effectiveness of interventions to increase physical activity. A systematic review. Am J Prev Med. 2002;22:73-107.

12. World Health Organization. Physical status: the use and interpretation of anthropometry. Geneva: WHO; 1995. Technical Report no 854.

13. Strong WB, Malina RM, Blimkie CJ, Daniels SR, Dishman RK, Gutin B, et al. Evidence based physical activity for school-age youth. J Pediatr. 2005;146:732-7.

14. Greenacre M. Correspondence analysis of the Spanish National Health Survey. Gac Sanit. 2002;16:160-70.

15. Blundell JE, King NA. Physical activity and regulation of food intake: current evidence. Med Sci Sports Exerc. 1999;31(11 Suppl):S573-83

16. Moore MS, Dodd CJ, Welsman JR, Armstrong N. Short-term appetite and energy intake following imposed exercise in 9- to 10-year-old girls. Appetite. 2004;43:127-34.

17. da Costa IR, Taddei JA, Colugnatti F. Obesity among children attending elementary public schools in Sao Paulo, Brazil: a casecontrol study. Public Health Nutr. 2003;6:659-63.

18. Wells JC, Davies PS. Diet and behavioural activity in 12-weekold infants. Ann Hum Biol. 1995;22:207-15.

19. Worobey J. Feeding method and motor activity in 3-month-old human infants. Percept Mot Skills. 1998;86:883-95.

20. Taddei JAAC, Colugnati FAB, Rodrigues EM, Sigulem DM, Lopez FA. Desvios nutricionais em menores de cinco anos. São Paulo:Universidade Federal de São Paulo; 2002

21. Oehlschlaeger MH, Pinheiro RT, Horta B, Gelatti C, San'tana P. Prevalence of sedentarism and its associated factors among urban adolescents. Rev Saude Publica. 2004;38:157-63.

22. Instituto Brasileiro de Geografia e Estatística. Perfil das mulheres responsáveis pelos domicílios no Brasil: estudos e pesquisas. Rio de Janeiro: IBGE; 2002. Informações Demográficas no 8.

23. Sawaya AL, Martins $P$, Hoffman D, Roberts $S B$. The link between childhood undernutrition and risk of chronic diseases in adulthood: a case study of Brazil. Nutr Rev. 2003;61:168-75.

24. Doak CM, Adair LS, Bentley M, Monteiro C, Popkin BM. The dual burden household and the nutrition transition paradox. Int J Obes (Lond). 2005;29:129-36.

25. Iyer S, Monteiro MF. The risk of child and adolescent mortality among vulnerable populations in Rio de Janeiro, Brazil. J Biosoc Sci. 2004;36:523-46.

26. Centers for Disease Control and Prevention (CDC). Physical activity levels among children aged $9-13$ years - United States, 2002. MMWR Morb Mortal Wkly Rep. 2003;52:785-8.

27. Hanley M, Taddei JAAC, Setzer J, Fonseca APP. Infant and youth survival indicators disaggregated by district income. São Paulo City, Brazil. Pediatr Nutr. 2002;4:3-13.

28. Telama R, Yang X, Viikari J, Välimäki I, Wanne O, Raitakari O. Physical activity from childhood to adulthood. A 21-year tracking study. Am J Prev Med. 2005;28:267-73.

29. Kohl III HW, Fulton JE, Caspersen CJ. Assessment of physical activity among children and adolescents: a review and synthesis. Prev Med. 2000;31:S54-S76.

Correspondence:

Mario Maia Bracco

Rua Loefgreen, 1647 - Vila Clementino

CEP 04040-032 - São Paulo, SP - Brazil

Tel./Fax: + 55 (11) 5573.1246

E-mail:mmb@bracco.com.br,nutsec@yahoo.com.br 